\title{
Stimulation of photosynthesis and consequent oxygen production in anoxic bottom water by supply of low-intensity light through an optical fiber
}

\author{
USCHAREE RUANGDEJ AND KIMIO FUKAMI* \\ Laboratory of Aquatic Environmental Science, Kochi University, Nankoku, Kochi 783-8502, Japan
}

\begin{abstract}
In order to enhance the oxygen production in anoxic bottom water using light, the bottom water and sediment collected in different seasons from a coastal area were incubated under irradiance treatments of 7 and $15 \mu \mathrm{E} / \mathrm{m}^{2}$ per s by halogen lamp provided through an optical fiber. The dissolved oxygen (DO) concentrations increased from $3.6 \mathrm{mg} / \mathrm{L}$ to $7.1 \mathrm{mg} / \mathrm{L}$ in the $15 \mu \mathrm{E} / \mathrm{m}^{2}$ per s irradiance treatment, while in the dark control the DO concentrations decreased to $1.1 \mathrm{mg} / \mathrm{L}$ in June. Along with the oxygen increase, chlorophyll a concentration increased from $0.24 \mu \mathrm{g} / \mathrm{L}$ to $1.35 \mu \mathrm{g} / \mathrm{L}$ while inorganic nitrogen and phosphorus decreased. These results indicate that low-intensity light is effective in stimulating photosynthesis of coastal bottom water and for net production of DO, especially in summer. It is a promising way to improve the anoxic bottom environment.
\end{abstract}

KEY WORDS: anoxic, irradiance, optical fiber, oxygen production, photosynthesis.

\section{INTRODUCTION}

The aquaculture coastal area has an excessive supply of nutrients. The excess organic matter sinks to deeper layers, which leads to high oxygen consumption rates during decomposition. ${ }^{1}$ Thermal stratification, which inhibits vertical mixing, causes anoxic conditions over the bottom layer in summer. ${ }^{2}$ The auto shading limits the oxygen production in bottom water due to decreased light penetration. The anoxic conditions will lead to many problems, such as decrease in microbial activity, loss in biodiversity, and accumulation of toxic gas, methane and hydrogen sulfide in the coastal bottom water environment. ${ }^{3}$ Therefore dissolved oxygen (DO) concentrations are fundamental to keep the ecosystem healthy and for keeping the bottom environment sustainable.

Uranouchi Inlet, Kochi Prefecture in Japan, where many fish cages of aquaculture are set, is a semiclosed small inlet that is representative of such conditions. ${ }^{4}$ In Uranouchi Inlet the oxygen is depleted over the bottom layer in summer. ${ }^{5}$ The bottom layer in this inlet becomes anoxic and rich in organic and inorganic nutrients. ${ }^{5,6}$ Several ideas have been developed to improve anoxic

\footnotetext{
*Corresponding author: Tel: 81-88-864-5152. Fax: 81-88-864-5157. Email: fukami@cc.kochi-u.ac.jp Received 8 October 2003. Accepted 13 January 2004.
}

condition of such bottom layers. The technological method (i.e. aeration with pressured air) uses electricity. The benefit of this method is a swift change in DO concentration. However, it has many disadvantages in that its energy consumption is high.

It has been noted that large amounts of dissolved inorganic nitrogen (DIN) and phosphate (DIP), and chlorophyll $a$ are found in the deeper layer, ${ }^{5}$ but no light penetrates to the deep layer in summer. Another option to increase dissolved oxygen over the bottom layer, therefore, is to enhance the photosynthetic process. ${ }^{7}$ By introducing a small amount of solar energy through an optical fiber to the deep aphotic layer, the anoxic condition of the bottom environment can be changed. ${ }^{7}$ We have already tried to increase the DO concentration by stimulating photosynthesis with dim light through an optical fiber and showed that an irradiance treatment of $7 \mu \mathrm{E} / \mathrm{m}^{2}$ per s would be the minimum required for net DO production. ${ }^{7}$ However, there is no information about the changes in concentrations of inorganic nutrients, nor for chlorophyll $a$ in detail, along with the DO increasing during the incubation.

The purpose of the present study was therefore to determine the effect of low-intensity light on oxygen production and the simultaneous changes in other parameters, under halogen lamp carried through optical fiber, in bottom water in different seasons. 


\section{MATERIALS AND METHODS}

\section{Experimental design}

Laboratory experiments were conducted with bottom water and sediment obtained from Uranouchi Inlet, which is located in Kochi Prefecture, Japan $\left(33^{\circ} 26^{\prime} \mathrm{N}, 133^{\circ} 24^{\prime} \mathrm{E}\right.$, Fig. 1). It is a semiclosed inlet, with a maximum depth of $16-17 \mathrm{~m} \cdot{ }^{6,8}$ Bottom water samples of $16 \mathrm{~m}$ depth at sampling station were collected monthly by a Niskin water sampler (5 L; General Oceanics, Miami, FL, USA) or a Bilge vacuum water pump (BP190-30; Hitachi, Tokyo, Jpan) and were transferred into the experimental unit of $10 \mathrm{~L}$ polyethylene brown bottles through polyvinyl pipe. Special attention was paid to minimize the oxygen contamination by air bubbles. For determining the oxic or anoxic condition of $16 \mathrm{~m}$ depth in the field, DO concentration of the sampling station was monitored weekly using the conductivity, temperature and depth (CTD) system (Idronaut, Ocean Seven model no. 301S; K. Engingeering, Tokyo, Japan).

Sediment samples were collected from the same sampling site using an Ekman-Birge grab sampler. Surface sediment of approximately $0-2 \mathrm{~cm}$ was collected using a spatula and was homogenized before transfer to the experimental unit. A total of $100 \mathrm{~g}$ of sediment was added to each bottle containing $10 \mathrm{~L}$ of bottom water. It was added by slowly pouring the sediment into the bottles, making sure there was no disturbance. To avoid nutrient replenishment, the bottles were shelved overnight so as to settle the sediments completely. ${ }^{9}$ The amount of sediment therefore was $1 \%(\mathrm{w} / \mathrm{v})$ of seawater.

These samples were incubated under dark and light conditions. To determine the irradiance in the incubation systems, the irradiance in Uranouchi Inlet was measured using a quantum meter (LICOR model LI-192SA). It was approximately $2000 \mu \mathrm{E} / \mathrm{m}^{2}$ per s as a maximum at $1-2 \mathrm{~cm}$ below the surface on a sunny day in summer. Seasonal change in irradiance at $16 \mathrm{~m}$ depth at the sampling site using a quantum meter (LI-COR) is given in Fig. 2 as the mean values of several sampling occasions (2-4 times a month) around 10:00 a.m. The average of light irradiance in $15 \mathrm{~s}$ was $0-15$ $\mu \mathrm{E} / \mathrm{m}^{2}$ pers at the maximum. Therefore, we selected $15 \mu \mathrm{E} / \mathrm{m}^{2}$ per s and $7 \mu \mathrm{E} / \mathrm{m}^{2}$ per s as just above the sediment surface in the incubation bottles, and dark $\left(0 \mu \mathrm{E} / \mathrm{m}^{2}\right.$ per s) as the incubation conditions. All the incubations were done in duplicate except for December, in which only one experiment was done. Supply of light was performed using halogen lamp (Aqua Beam AQHR-100, La Foret Engineering, Tokyo, Japan) through an optical fiber with a light : dark cycle of $12 \mathrm{~h}: 12 \mathrm{~h}$. Water surface in all incubation bottles was covered with small polypropylene balls $(10 \mathrm{~mm}$ in diameter) to prevent oxygen contamination from the air. The incubations were conducted in a water bath, the temperatures of which were set as in situ $\left(16.0^{\circ} \mathrm{C}-27.5^{\circ} \mathrm{C}\right)$, for $18-20$ days.

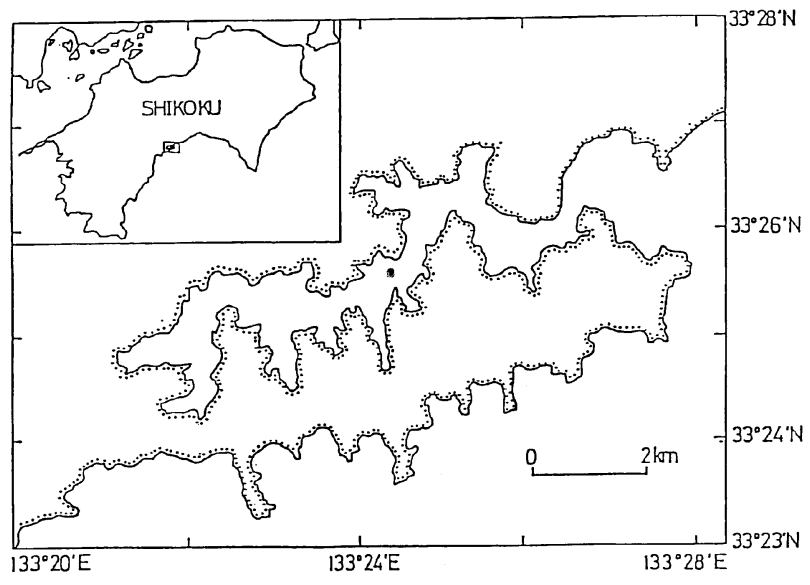

Fig. 1 Location of the sampling station ( $)$ in Uranouchi Inlet in Kochi Prefecture, Japan.

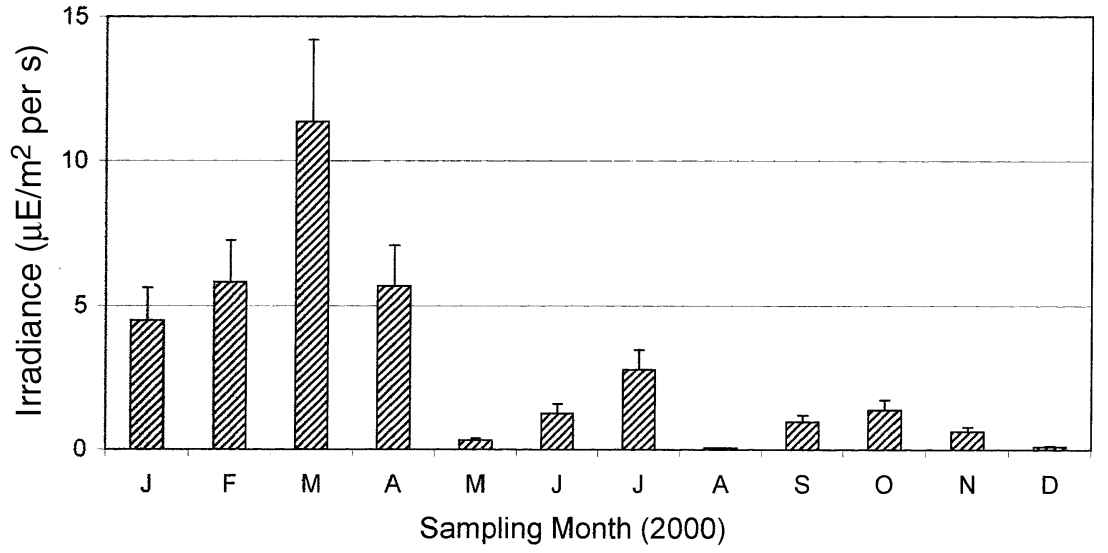

Fig. 2 Seasonal changes in the irradiance $\left(\mu \mathrm{E} / \mathrm{m}^{2}\right.$ per s) at $16 \mathrm{~m}$ depth for the sampling station throughout the year 2000 as an average of several sampling occasions. Bars mean range of data $(n=2-4)$. 
During the incubation, changes in DO concentration were measured every day at $10 \mathrm{~cm}$ above the sediment surface using DO meter (OM-14; Horiba, Kyoto, Japan). In order to obtain the representative data of the whole water phase while not disturbing the sediment and avoiding oxygen contamination, slight stirring by DO probe during the measurement was done. The precision of this DO meter was $\pm 0.01 \mathrm{mg} / \mathrm{L}$, and all dissolved oxygen values were corrected for salinity and temperature. The DO values obtained by DO meter were compared with those of Winkler's method and the difference between the two was $\pm 0.2 \mathrm{mg} / \mathrm{L}(n=3)$.

\section{Chlorophyll $a$ and nutrient analyses}

At the beginning and the end of incubations, chlorophyll $a$ and its degradation products (pheopigments) in water were determined. In situ bottom water samples for the beginning and subsamples in the incubation bottles for the end of experiments were analyzed. One to three liters of seawater were filtered through Whatman GF/F glass fiber filters, then the filter papers were immediately frozen $\left(-20^{\circ} \mathrm{C}\right)$ until analyzed. Chlorophyll $a$ concentrations were determined spectrophotometrically (Ultrospec 2000, Pharmacia Biotech) after extracting with $90 \%$ acetone solution. ${ }^{10}$ In addition, we determined the amount of pheopigments (chlorophyll $a$ degradation products), in samples collected after April 2000. Therefore, we did not have pheopigments data in March 2000. By differences of the absorbance of $663 \mathrm{~nm}$ (correspond to SCOR/ UNESCO) before ('net' chlorophyll $a$ ) and after (pheopigments) adding $1 \mathrm{M} \mathrm{HCl}$, the percentages of pheopigments in the total ('net' chlorophyll $a$ plus pheopigments) were calculated as a tentative indicator of 'activity condition' of phytoplankton after Lorenzen. ${ }^{11}$

For monitoring the inorganic nutrients, subsamples of water $8-10 \mathrm{~cm}$ above the sediment surface were taken from incubation systems every 3 days, filtered through precombusted GF/F glass fiber filters, and kept frozen $\left(-20^{\circ} \mathrm{C}\right)$ until analysis. Filtrates were used for analyzing the amount of inorganic nitrogen $\left(\mathrm{NH}_{4}{ }^{+}, \mathrm{NO}_{2}^{-}\right.$, and $\left.\mathrm{NO}_{3}^{-}\right)$, and inorganic phosphorus $\left(\mathrm{PO}_{4}{ }^{3-}\right)$ with an automatic analyzer (Bran+Luebbe TRAACS 800, Osaka, Japan).

\section{RESULTS}

\section{Changes in the dissolved oxygen concentration}

Vertical and seasonal changes in DO concentration at the sampling station are illustrated in Fig. 3. Anoxic water $<2 \mathrm{mg} / \mathrm{L}$ started to appear in the bottom layer from the middle of June and continued until late September. In mid-summer (August), a completely anoxic water mass was distributed in the bottom layer in Uranouchi Inlet.

Changes in DO concentration during incubation of samples collected in different seasons are shown in Fig. 4 as mean values of the duplicate (except in December). The DO concentration at the beginning of the experiment using samples from 2 March 2000 was approximately $7.4 \mathrm{mg} / \mathrm{L}$ (Fig. 4a). It decreased less than $5.0 \mathrm{mg} / \mathrm{L}$ in the first 6 days in all three systems (dark, $7 \mu \mathrm{E} / \mathrm{m}^{2}$ per s, 15 $\mu \mathrm{E} / \mathrm{m}^{2}$ per s). The DO concentration decreased continuously until the end of incubation in the treatment without light (dark condition), ending at
Fig. 3 Depth-time variation of dissolved oxygen (DO) concentration at the sampling site in 2000. Oxygendepleted water less than $2 \mathrm{mg} / \mathrm{L}$ is marked by a solid line.

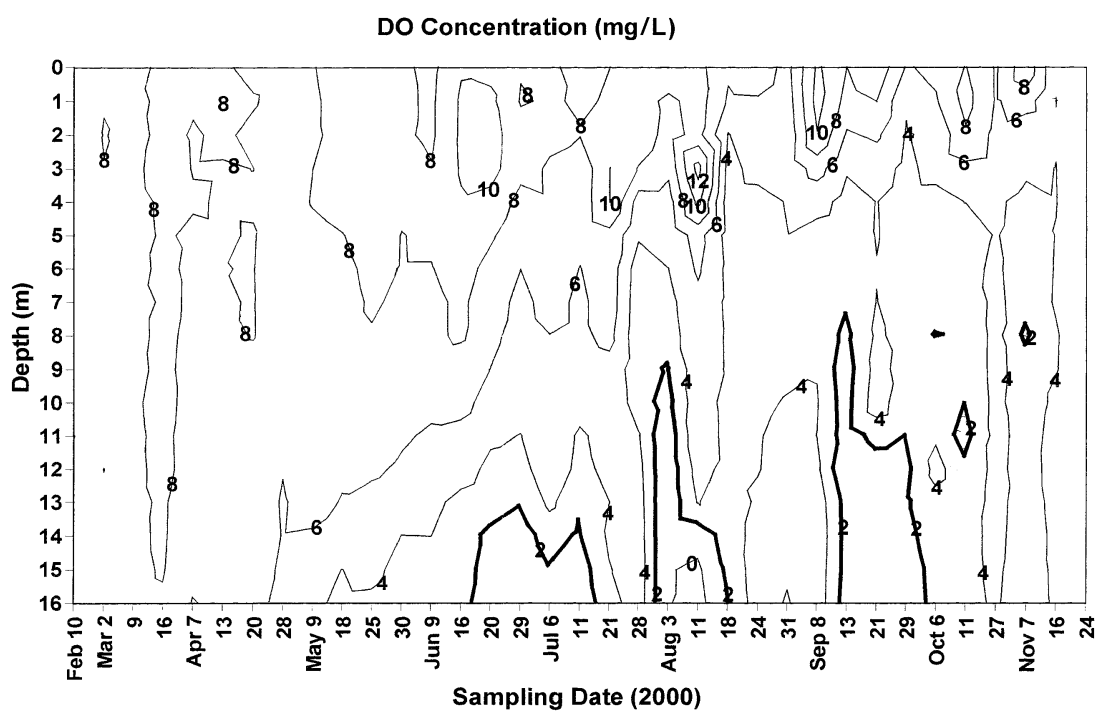


(a) MAR 2, 2000

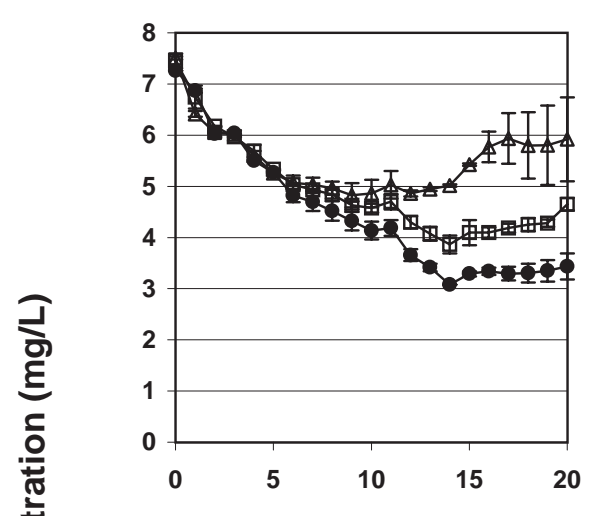

(c) SEP 8, 2000

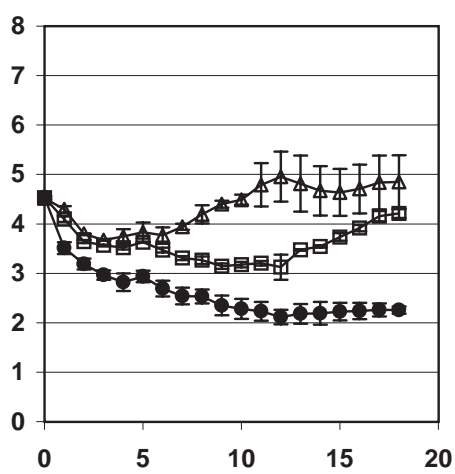

(b) JUN 16, 2000

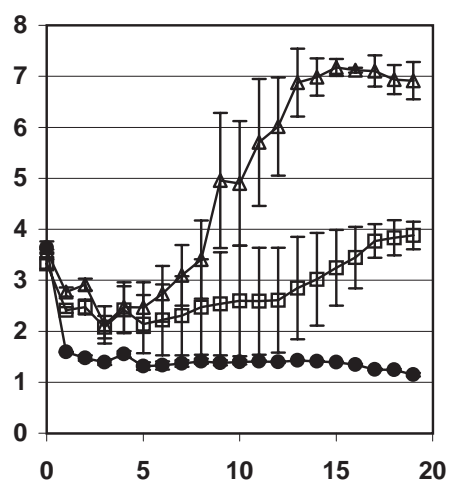

(d) DEC 14, 2000

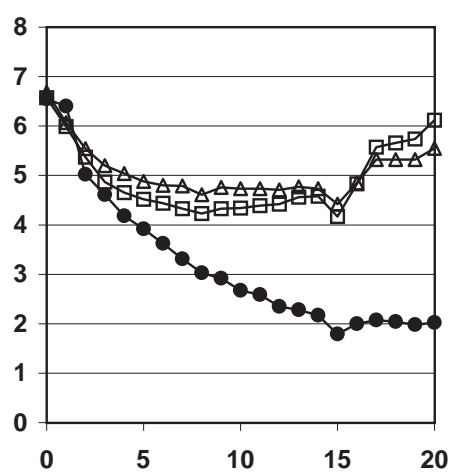

Incubation Time (Day)

$\rightarrow$ Dark $\quad \square 7 \mu \mathrm{E} / \mathrm{m}^{2}$ pers $\quad \triangle 15 \mu \mathrm{E} / \mathrm{m}^{2}$ per s

Fig. 4 Changes in dissolved oxygen (DO) concentration $(\mathrm{mg} / \mathrm{L})$ as average values of duplicate samples during the incubation in four different representative seasons. Bars mean range of duplicate. (In December, due to technical difficulty, only one experiment was done.)
$3 \mathrm{mg} / \mathrm{L}$ (Fig. 4a). In the incubation system with an irradiance treatment of $7 \mu \mathrm{E} / \mathrm{m}^{2}$ per s, DO also decreased at a constant rate until it reached $4.6 \mathrm{mg} / \mathrm{L}$, although decrease was slower than that for the dark treatment (Fig. 4a). However, the effect on DO concentration of the $15 \mu \mathrm{E} / \mathrm{m}^{2}$ per s irradiance treatment was evident, and the DO concentration increased from $4.8 \mathrm{mg} / \mathrm{L}$ to $5.9 \mathrm{mg} /$ L after day 12 (Fig. 4a).

In the experiment using samples collected on 16 June 2000, the initial DO concentration decreased to $3.5 \mathrm{mg} / \mathrm{L}$ because of thermal stratification at the sampling site (Fig. 4b). The DO concentration in the dark treatment decreased to $1.5 \mathrm{mg} / \mathrm{L}$ on the first day and did not change until the last day of incubation. In contrast, the $15 \mu \mathrm{E} / \mathrm{m}^{2}$ per s irradiance treatment stimulated remarkable net oxygen production after the fifth day and it reached a maximum of $7.1 \mathrm{mg} / \mathrm{L}$ on the 15th day (Fig. $4 \mathrm{~b}$ ). The $7 \mu \mathrm{E} / \mathrm{m}^{2}$ per s irradiance treatment also stimu- lated oxygen production although it was not as high (Fig. 4b).

In the experiment using samples collected on 8 September 2000 (Fig. 4c), the initial DO concentration recovered to $4.6 \mathrm{mg} / \mathrm{L}$ because of breakdown of stratification. While in dark incubation, the DO concentration decreased to $2.3 \mathrm{mg} / \mathrm{L}$ until the 18 th day. The net DO production was observed in the light treatment but the effects of irradiance were less than those in the summer month of June (Fig. 4b,c).

In the experiment using samples collected on 14 December 2000 (Fig. 4d), DO concentrations before the incubation were approximately 6.5 $\mathrm{mg} / \mathrm{L}$ because of complete vertical mixing in the field. The DO concentrations in the two irradiance treatments ( 7 and $15 \mu \mathrm{E} / \mathrm{m}^{2}$ per s) did not decrease as much as that in the dark and increased after the 15th days, whereas the dark treatment continued to decrease in DO concentration (Fig. 4d). As the 
seasons progressed to winter the effects of irradiance gradually diminished, although in the dark the DO concentration always decreased consistently (Fig. 4).

\section{Changes in the chlorophyll $a$ concentration}

Figure 5 shows the concentrations of chlorophyll $a$, and the percentages of pheopigments (except for the sample of March), at the beginning and the end of incubation of four experiments as the representative of different seasons. All figures are shown as the average values of two replicate. Although the initial concentrations of chlorophyll $a$ were relatively high in the samples collected in March and December (Fig. 5a,d), they stayed low $(<0.5 \mu \mathrm{g} / \mathrm{L})$ during the summer months of June and September (Fig. 5b,c). Concentrations of chlorophyll $a$ in the dark control always decreased during the incubation period. Those under the light supply, in contrast, decreased in March and December but increased in June and September. However, the chlorophyll $a$ concentrations after the incubation in the light supply were consistently higher than those in the dark control (Fig. 5). In the summer period in particular, the chlorophyll $a$ concentrations in irradiance treatments increased from $0.2 \mu \mathrm{g} / \mathrm{L}$ to approximately $1.5 \mu \mathrm{g} / \mathrm{L}$ in June, and from $0.5 \mu \mathrm{g} / \mathrm{L}$ to $1.7 \mu \mathrm{g} / \mathrm{L}$ in September, respectively (Fig. 5b,c). The final chlorophyll $a$ concentrations in the irradiance treatments were approximately sevenfold and 10-fold greater than those in the dark control, respectively.

In addition to the quantitative differences, we also obtained qualitative differences in chlorophyll $a$. As was mentioned earlier, we did not obtain data in March (Fig. 5a). The pheopigments proportion was similar at the beginning but differed at the end. Although the percentages of pheopigments in the dark usually increased to, or remained at, high values of around $80 \%$ (Figs 5B.C.D), the percentages of pheopigments in the irradiance treatments were always lower than those of the dark control, despite the decrease in June (Fig. 5b), or the slight increase in September or decrease in December. These results indicate that phytoplankton in the dark control contained more degraded products of chlorphyll $a$ than that (a) MAR 2, 2000

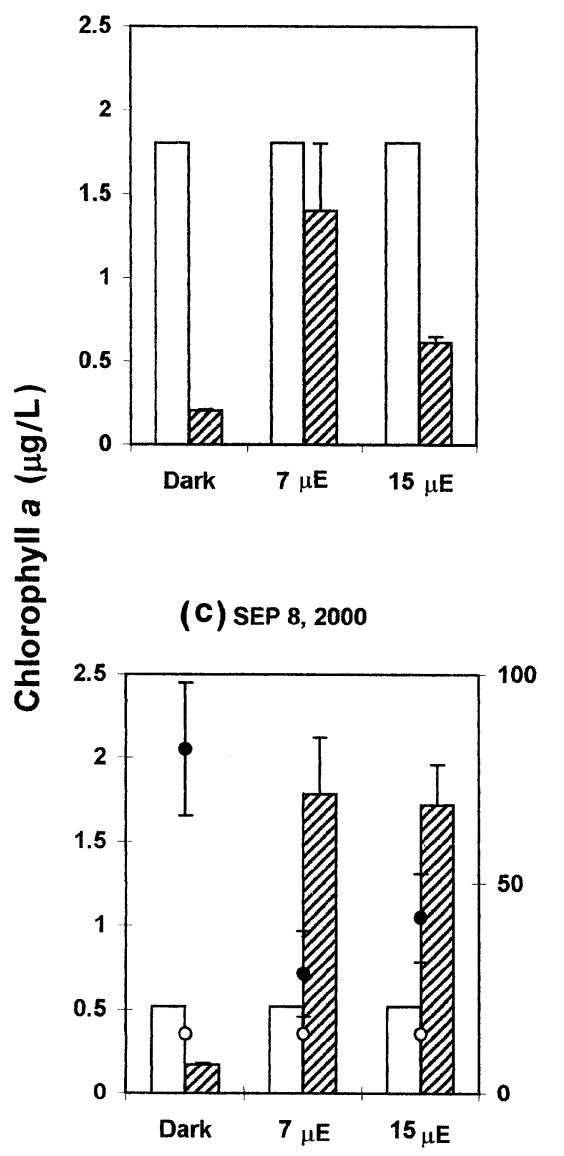

(b) JUN 16, 2000
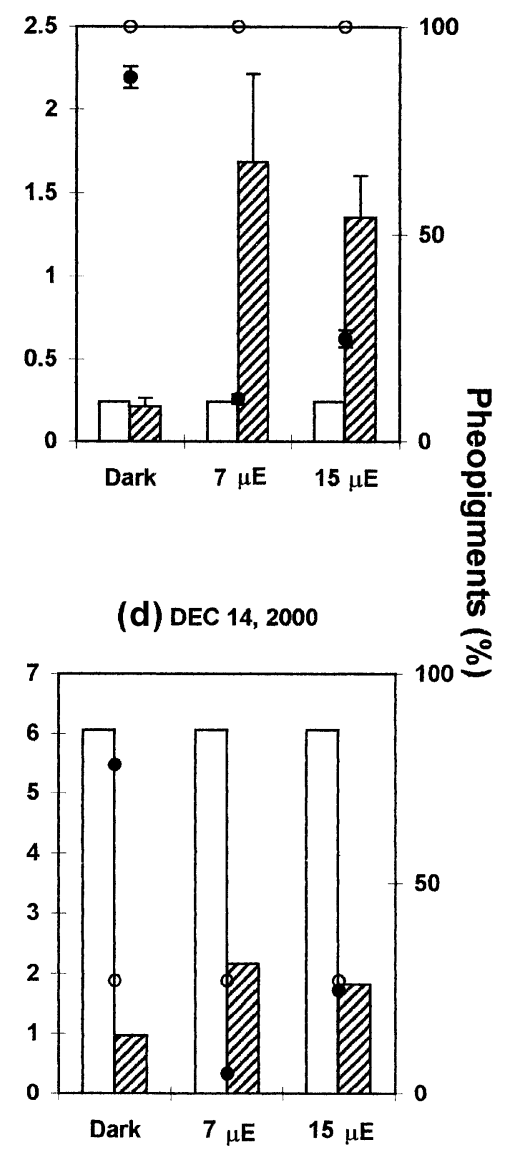

Fig. 5 Changes in chlorophyll $a$ concentration $(\mu \mathrm{g} / \mathrm{L})$ in seawater $(\square)$ before and ( $\square$ ) after the incubation, and pheopigments percentage $(\bigcirc)$ before and ( ) after the incubation in four different representative seasons. Data are given as the average values of duplicate samples. Bars mean range of duplicates. Note that there are no data for pheopigments in (a), and scale of chlorophyll $a$ in (d) was adjusted for the concentration obtained. $\mu \mathrm{E}, \mu \mathrm{E} / \mathrm{m}^{2}$ per $\mathrm{s}$. 
in the light conditions, and that the phytoplankton became to possess more 'net' chlorophyll $a$ during incubation under irradiance treatments of 7 or $15 \mu \mathrm{E} / \mathrm{m}^{2}$ per s.

\section{Changes in inorganic nutrient concentration}

Changes in the concentrations of DIN and DIP during incubation are given as the average value of the two samples in Fig. 6 (DIN) and Fig. 7 (DIP). The initial concentrations of DIN and DIP were significantly higher in summer (June, Figs 6b,7b; September, Figs 6c,7c) when the initial concentrations of chlorophyll $a$ were lower (Fig. 5b,c), while those of the inorganic nutrients in March and December (when the initial amounts of chlorophyll $a$ were higher), were lower (Figs 6a,d,7a,d, respectively). Although DIN concentrations in the samples of dark control during the incubation increased or decreased depending on the season, those of the irradiance treatments were consistently lower than those for the dark condition (Fig. 6). In June and September, DIN concentrations decreased dramatically during the incubation under $15 \mu \mathrm{E} / \mathrm{m}^{2}$ per s (Fig. 6b,c).

In contrast, the fluctuation in DIP produced unexpected patterns (Fig. 7). In March and December, DIP concentrations increased consistently in all three treatments without any significant difference among the three (Fig. 7a,d). In June, DIP decreased even in the dark control (Fig. 7b), and it increased only in the dark and in the $7 \mu \mathrm{E} / \mathrm{m}^{2}$ pers treatment in September (Fig. 7c). However, the concentration of DIP under the $15 \mu \mathrm{E} / \mathrm{m}^{2}$ per s treatment generally had the lowest values throughout the incubation and seasons (Fig. 7). (a) MAR 2, 2000

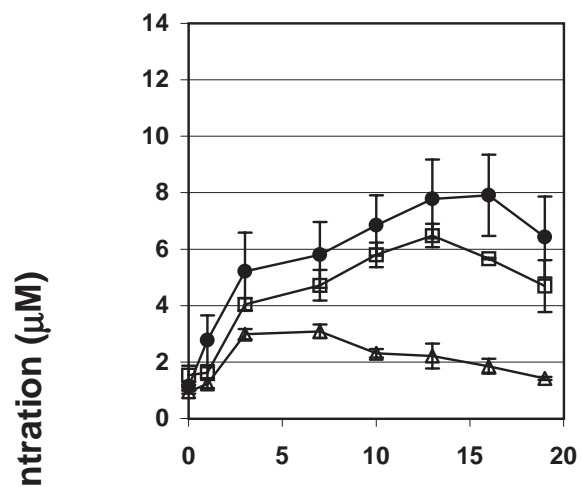

(c) SEP 8, 2000

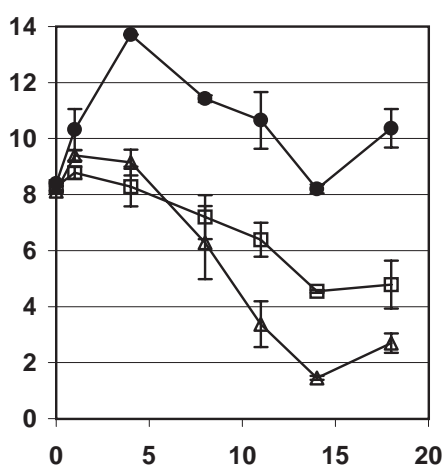

(b) JUN 16, 2000

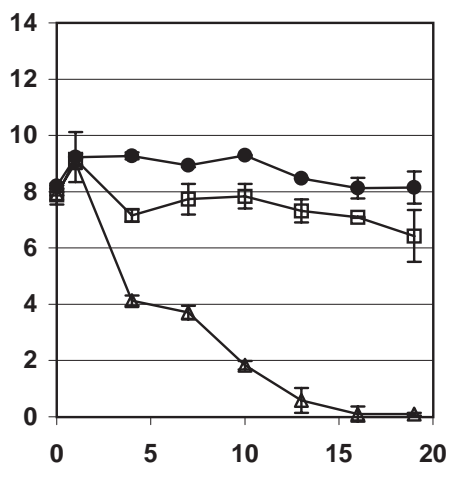

(d) DEC 14, 2000

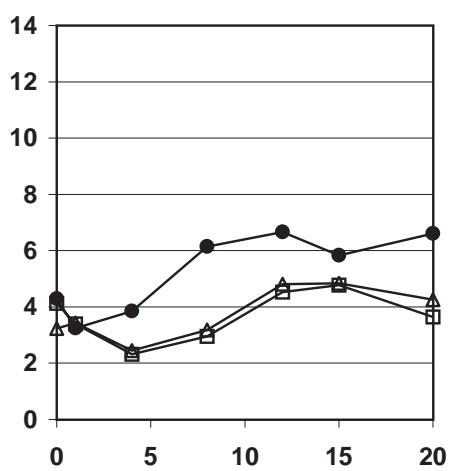

Incubation time (Day)
Fig. 6 Changes in the concentration of dissolved inorganic nitrogen (DIN) as the average of duplicate samples during the incubation in four different representative seasons. Bars mean range of duplicate. (In December, due to technical difficulty, only one experiment was done.) 
(a) MAR 2, 2000

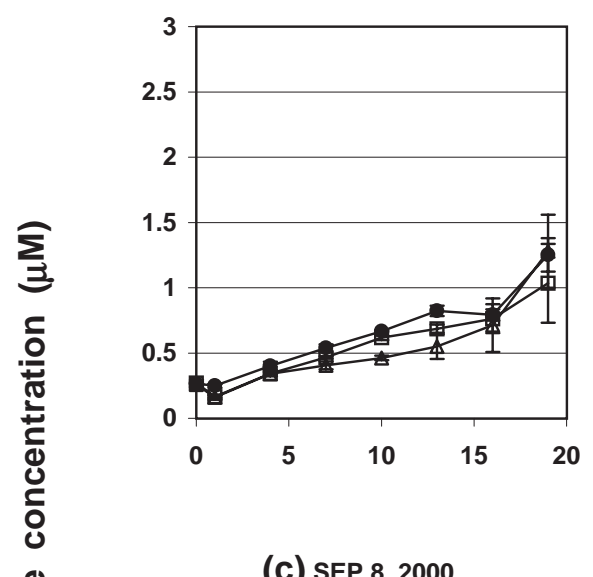

(c) SEP 8, 2000

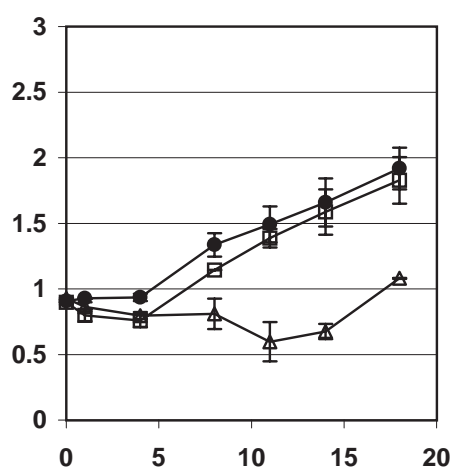

(b) JUN 16, 2000

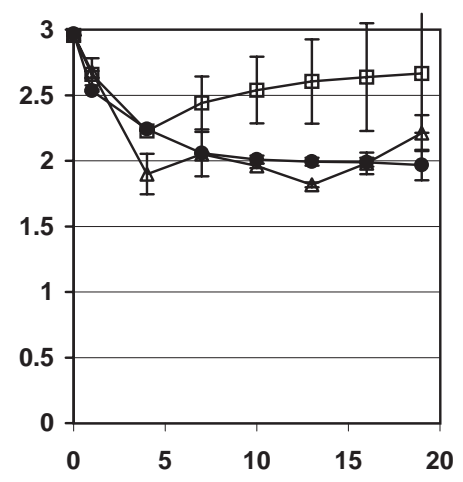

(d) DEC 14, 2000

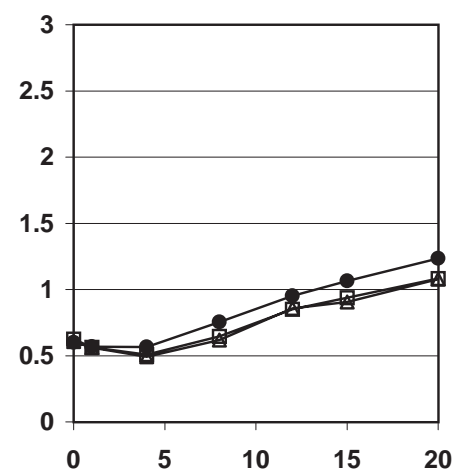

of orthophosphate $\left(\mathrm{PO}_{4}^{3-}\right)$ as the average of duplicate samples during the incubation in four different representative seasons. Bars mean range of duplicate. (In December, due to technical difficulty, only one experiment was done.)

\section{DISCUSSION}

Most of the coastal area, where intensive aquaculture is carried out, has an excess nutrient load ${ }^{7}$ and the bottom environments are usually anoxic due to stratification of the water column in summer. ${ }^{6,12,13}$ In the sampling site of Uranouchi Inlet, the bottom environment in mid-summer was completely anoxic (Fig. 3). For improving such an anoxic bottom environment, we proposed and evaluated the possibility of generating DO in the bottom environments by introducing dim light through an optical fiber., ${ }^{5,7}$

Results obtained in the present study reveal that the dark incubation of the bottom sediment-water systems produced consistent DO consumption throughout the year (Fig. 4). In contrast, the DO concentration always increased significantly under the $15 \mu \mathrm{E} / \mathrm{m}^{2}$ per s irradiance treatment. This sug- gests that the activity of phytoplankton in the bottom water was stimulated quickly and that they produced more oxygen than was consumed by respiration and, as a result, DO concentration increased ('net' DO production was positive) in bottom environments (Fig. 4). Therefore, DO concentration was the result of the difference in oxygen production and consumption for the whole system. The $15 \mu \mathrm{E} / \mathrm{m}^{2}$ per s irradiance treatment usually produced a level of DO higher than $5 \mathrm{mg} /$ $\mathrm{L}$, which is the optimum criterion for living organisms. ${ }^{14}$ Light supply of $7 \mu \mathrm{E} / \mathrm{m}^{2}$ per s, although stimulating oxygen production in the summer months of June and September (Fig. 4b,c), did not produce a DO increase in March (Fig. 4a). This low oxygen production would be due to the initial concentration of inorganic nutrient. Higher DIN concentrations of approximately $8-10 \mu \mathrm{M}$ were obtained due to stratification in summer (June and 
September), while in March and December it was 1-4 $\mu \mathrm{M}$ (Fig. 6). This was a result of less vertical mixing in summer. The very high oxygen production observed in June (Fig. 4 b) would be due to high DIN and DIP at the beginning of incubation (Figs 6b,7b).

Another reason for the high increase in DO in summer but not in winter is the background light intensity at the sampling site and the photoadaptation of phytoplankton in bottom water. When water samples were collected in summer, in which season the compensation depth was less than $10 \mathrm{~m}$ (from the data of vertical profile of actual irradiance, data not shown) and only low light intensity reached to $16 \mathrm{~m}, 7 \mu \mathrm{E} / \mathrm{m}^{2}$ per s seemed to be enough for stimulating oxygen production (Fig. 4b,c). However, in the other seasons when the water transparency was relatively high and a higher light intensity reached to the bottom, the same irradiance treatment of $7 \mu \mathrm{E} / \mathrm{m}^{2}$ per s had little effect on oxygen production (Fig. 4a,d). The photosynthesis quotient is not a stable property of a cell but changes depending on the previous history of the species and environment conditions. ${ }^{15,16}$ It has been reported that phytoplankton change their size and increase the amount of per-cell pigments under low light intensity. ${ }^{17,18}$ Phytoplankton communities or species adapted to low light had a much higher photosynthetic capacity than those adapted to high-intensity light. ${ }^{19}$ Although we did not determine the seasonal changes in community structure of phytoplankton in the bottom water in the present study, there is a possibility that seasonal differences of irradiance effects on DO production were due to the phytoplankton species that predominated in bottom water.

Our reasoning is that light is the most important limiting factor for the phytoplankton in bottom water in summer, and that supply of low light will cause the plankton to start photosynthesis. Therefore, in the other seasons when available nutrient concentration and/or water temperature would be more important limiting factors than light intensity, this idea is not applicable. However, in such seasons we do not need to increase DO concentration because the bottom water will already have a sufficient amount of DO.

Along with increase in DO concentration, the amount of chlorophyll $a$ increased remarkably in June and September (Fig. 5b,c), and the concentration of DIN decreased rapidly (Fig. 6b,c) under the irradiance treatment during the incubation period. This confirmed again that the mechanism of oxygen production was due to photosynthetic activity. Concentrations of chlorophyll $a$ at the end of incubation under the irradiance treatments were consistently higher than those in the dark treatment
(Fig. 5). This tendency was much more significant in June and September (Fig. 5b,c). In addition, the proportion of pheopigments in the total amount of chlorophyll $a$ (net chlorophyll $a$ plus pheopigments) at the end of the experiment decreased under the irradiance treatments (Fig. 5b,c). As mentioned previously, pheopigment is considered to be degraded chlorophyll $a{ }^{11}$ Very low percentages of pheopigments were found in the middle of blooming, when most phytoplankton would grow actively, and a high proportion of pheopigments was often observed in the decay period of plankton bloom. ${ }^{20}$ Therefore, a high proportion of pheopigments indicates that the plankton have a low activity, and a low proportion means a high plankton activity. The present findings that the amount of chlorophyll $a$ increased and that the proportion of pheopigments decreased during incubation under the 7 and $15 \mu \mathrm{E} / \mathrm{m}^{2}$ per s irradiance treatments indicate that the irradiance treatment stimulated the phytoplankton not only in terms of biomass but also in terms of activity in the bottom water.

From the results of the present study it is suggested that an irradiance treatment of $7 \mu \mathrm{E} / \mathrm{m}^{2}$ per s could enhance the oxygen production, and that the problem of anoxic condition in bottom water could be solved by supplying dim light in order to stimulate photosynthetic activity. In the present study we used the halogen lamp as a source of light. However, in future studies energyconsuming artificial light should be replaced by natural solar light. ${ }^{7}$ The concept of introducing natural solar light into bottom environments through an optical fiber is promising and we expect that this system will be applied to the field in the future.

\section{ACKNOWLEDGMENTS}

The authors thank Professor Dr T Nishijima and Dr $M$ Adachi for their valuable suggestions and help related to the study, Dr A B Patel, Mr R Nakajima, Mr S Oka and students of the laboratory of Aquatic Environmental Science (LAQUES) for their kind help in sampling and analyses, and the staff of the Marine Biological Research Center Usa (Japan) for their help during sampling and/or chemical or biological analysis. The present study was supported in part by a grant-in-aid of Marino Forum 21.

\section{REFERENCES}

1. Møhlenberg F. Effect of meteorology and nutrient load on oxygen depletion in a Danish micro-tidal estuary. Aquat. Ecol. 1999; 33: 55-64. 
2. Beutel MW. Oxygen consumption and ammonia accumulation in the hypolimnion of Walker Lake, Nevada. Hydrobiologia 2001; 466: 107-117.

3. Revsbech NP, Jørgensen BB, Blackburn TH, Cohen Y. Microelectrode studies of the photosynthesis and $\mathrm{O}_{2}, \mathrm{H}_{2} \mathrm{~S}$, and $\mathrm{pH}$ profiles of a microbial mat. Limnol. Oceanogr. 1983; 28: 1062-1074.

4. Fukami K, Nishijima T, Murata H, Doi S, Hata Y. Distribution of bacteria influential on the development and the decay of Gymnodinium nagasakiense red tide and their effects on algal growth. Nippon Suisan Gakkaishi 1991; 57: 2321-2326.

5. Fukami K, Nakajima R, Patel AB, Nishijima T. Bioremediation by using optical fibers and psychrophilic bacteria. Proceeding of the joint conference. MEDCOAST 99-EMECS 99, Land-Ocean Interacts: Managing Coastal Ecosystems 1999; 1: 399-408.

6. Patel AB, Fukami K, Nishijima T. Regulation of seasonal variability of aminopeptidase activities in surface and bottom waters of Uranouchi Inlet, Japan. Aquat. Microb. Ecol. 2000; 21: 139-149.

7. Fukami K, Ruangdej U, Patel AB, Nishijima T. Improvement of eutrophic coastal bottom environments by using an optical fiber and effective psychrophilic bacteria. Fish. Sci. 2002; 68: $617-620$.

8. Fukami K, Murata N, Morio Y, Nishijima T. Distribution of heterotrophic nanoflagellates and their importance as the bacterial consumer in a eutrophic coastal seawater. $J$. Oceanogr. 1996; 52: 399-407.

9. Karim MA, Fukami K, Patel AB. Enhancement of inorganic nutrient regeneration in a eutrophic sediment-bottom water complex system by adding effective indigenous bacteria. Fish. Sci. 2003; 69: 1146-1157.

10. SCOR/UNESCO. Determination of Photosynthetic Pigments in Seawater. Monographs on Oceanographic Methodology 1. UNESCO Publication Center, New York. 1966.
11. Lorenzen CJ. Determination of chlorophyll and pheopigments: spectrophotometric equations. Limnol. Oceanogr. 1967; 12: 343-346.

12. Holmer M, Kristensen E. Seasonality of sulfate reduction and pore water solutes in a marine fish farm sediment: the importance of temperature and sedimentary organic matter. Biogeochemistry 1996; 32: 15-39.

13. Sakami T, Abo K, Takayanagi K, Toda S. Effects of water mass exchange on bacterial communities in an aquaculture area during summer. Estuarine Coastal Shelf Sci. 2003; 56: 111-118.

14. US Environmental Protection Agency (USEPA). Ambient Water Quality Criteria for Dissolved Oxygen. US Environmental Protection Agency, Office of Water, Washington, DC. 1986.

15. Berner T, Dubinsky Z, Wyman K, Falkowski PG. Photoadaption and the 'package' effect in Dunaliella tertiolecta (Chlorophyceae). J. Phycol. 1989; 25: 70-78.

16. MacIntyre HL, Geider RJ. Regulation of Rubisco activity and its potential effect on photosynthesis during mixing in a turbid estuary. Mar. Ecol. Prog. Ser. 1996; 144: 247264.

17. Perry MJ, Talbot MC, Alberte RS. Photoadaption in marine phytoplankton: response to the photosynthetic unit. Mar. Biol. 1981; 62: 91-101.

18. Falkowski PG, LaRoche J. Acclimation to spectral irradiance in algae. J. Phycol. 1991; 27: 8-14.

19. MacIntyre HL, Kana TM, Anning T, Geider RJ. Photoacclimation of photosynthesis irradiance response curves and photosynthetic pigments in microalgae and cyanobacteria. J. Phycol. 2002; 38: 17-38.

20. Fukami K, Simidu U, Taga N. Change in a bacterial population during the process of degradation of a phytoplankton bloom in a brackish lake. Mar. Biol. 1983; 76: 253-255. 